\title{
Genetic and serologic surveillance of canine (CIV) and equine (EIV) influenza virus in Nuevo León State, México
}

\author{
Claudia B Plata Hipólito ${ }^{1}$, Sibilina Cedillo Rosales ${ }^{2}$, Nelson Obregón Macías ${ }^{3}$, Carlos E Hernández Luna ${ }^{4}$, Cristina \\ Rodríguez Padilla $^{1}$, Reyes S Tamez Guerra ${ }^{1}$, Juan Francisco Contreras Cordero ${ }^{\text {Corresp. } 1}$ \\ ${ }^{1}$ Laboratorio de Inmunología y Virología, Facultad de Ciencias Biológicas, Universidad Autónoma de Nuevo León, San Nicolás de los Garza, Nuevo León, \\ México \\ 2 Departamento de Virología, Facultad de Medicina Veterinaria y Zootecnia, Universidad Autónoma de Nuevo León, San Nicolás de los Garza, Nuevo León, \\ México \\ 3 Departmento de Grandes Especies, Facultad de Medicina Veterinaria y Zootecnia, Universidad Autónoma de Nuevo León, San Nicolás de los Garza, \\ Nuevo León, México \\ 4 Departamento de Química, Facultad de Ciencias Biológicas, Universidad Autónoma de Nuevo León, San Nicolás de los Garza, Nuevo León, México \\ Corresponding Author: Juan Francisco Contreras Cordero \\ Email address: juan.contrerascr@uanl.edu.mx
}

Background: Despite the uncontrolled distribution of the Influenza A virus through wild birds, the detection of canine (CIV) and equine influenza virus (EIV) in Mexico was absent until now. Recently, outbreaks of equine and canine influenza have been reported around the world; the virus spreads quickly among animals and there is potential for zoonotic transmission. Methods: Amplification of the Influenza A virus matrix gene from necropsies, nasal and conjunctival swabs from trash service horses and pets/stray dogs was performed through RT-PCR. The seroprevalence was carried out through Sandwich ELISA system using the M1 recombinant protein and polyclonal antibodies anti-M1. Results: The matrix gene was amplified from $13(19.11 \%)$ nasal swabs, 2 (2.94\%) conjunctival swabs and 5 (7.35\%) lung necropsies, giving a total of $20(29.41 \%)$ positive samples in a pet dog population. A total of 6 (75\%) positive samples of equine nasal swab were amplified. Sequence analysis showed $96-99 \%$ identity with sequences of Influenza A virus matrix gene present in H1N1, H1N2 and H3N2 subtypes. The phylogenetic analysis of the sequences revealed higher identity with matrix gene sequences detected from zoonotic isolates of subtype H1N1/2009. The detection of anti-M1 antibodies in stray dogs showed a prevalence of 123 (100\%) of the sampled population, whereas in horses, 114 (92.68\%) positivity was obtained. Conclusion: The results unveil the prevalence of influenza A virus in the population of horses and dogs in the state of Nuevo Leon, which could indicate a possible outbreak of equine and canine influenza in Mexico. We suggest that the prevalence of influenza virus in companion animals be monitored to investigate its epizootic and zoonotic potential, in addition to encouraging the regulation of vaccination in these animal species in order to improve their quality of life. 
1 Genetic and Serologic Surveillance of Canine (CIV)

2 and Equine (EIV) Influenza Virus in Nuevo León State,

3 México

4

5

6

7

8

9

10

11

12

13

14

15

16

17

18

19

20

21

22

23

24

25

26

27

28

29

30

31

32

33

34

35

36

37

38

Claudia Bernardette Plata Hipólito ${ }^{1}$, Sibilina Cedillo Rosales ${ }^{2}$, Nelson Obregón Macías ${ }^{3}$, Carlos Eduardo Hernandez Luna ${ }^{4}$, Cristina Rodríguez Padilla ${ }^{1}$, Reyes Tamez Guerra ${ }^{1}$, Juan Francisco Contreras Cordero ${ }^{1}$.

${ }^{1}$ Universidad Autónoma de Nuevo León, Facultad de Ciencias Biológicas, Laboratorio de Inmunología y Virología, México.

${ }^{2}$ Universidad Autónoma de Nuevo León, Facultad de Medicina Veterinaria y Zootecnia, Departamento de Virología, Escobedo, Nuevo León, México.

${ }^{3}$ Universidad Autónoma de Nuevo León, Facultad de Medicina Veterinaria y Zootecnia, Departamento de Grandes Especies, Escobedo, Nuevo León, México.

${ }^{4}$ Universidad Autónoma de Nuevo León, Facultad de Ciencias Biológicas, Departamento de Química, San Nicolás de los Garza, Nuevo León, México.

Corresponding Author:

Juan Francisco Contreras Cordero ${ }^{1}$

Cd. Universitaria s/n, San Nicolás de los Garza, Nuevo León, 66455, México.

Email address: contrerasjfco@gmail.com, juan.contrerascr@uanl.edu.mx .

\section{Abstract}

Background: Despite the uncontrolled distribution of the Influenza A virus through wild birds, the detection of canine (CIV) and equine influenza virus (EIV) in Mexico was absent until now. Recently, outbreaks of equine and canine influenza have been reported around the world; the virus spreads quickly among animals and there is potential for zoonotic transmission.

Methods: Amplification of the Influenza A virus matrix gene from necropsies, nasal and conjunctival swabs from trash service horses and pets/stray dogs was performed through RTPCR. The seroprevalence was carried out through Sandwich ELISA system using the M1 recombinant protein and polyclonal antibodies anti-M1.

Results: The matrix gene was amplified from 13 (19.11\%) nasal swabs, 2 (2.94\%) conjunctival swabs and 5 (7.35\%) lung necropsies, giving a total of 20 (29.41\%) positive samples in a pet dog population. A total of $6(75 \%)$ positive samples of equine nasal swab were amplified. Sequence analysis showed $96-99 \%$ identity with sequences of Influenza A virus matrix gene present in H1N1, H1N2 and H3N2 subtypes. The phylogenetic analysis of the sequences revealed higher identity with matrix gene sequences detected from zoonotic isolates of subtype H1N1/2009. The

Peer) reviewing PDF | (2019:05:37519:2:2:NEW 9 Nov 2019) 
39

40

41

42

43

44

45

46

47

48

49

50

51

\section{2}

53

54

55

56

57

58

59

60

61

62

63

64

65

66

67

68

69

70

71

72

73

74

75

76

77

detection of anti-M1 antibodies in stray dogs showed a prevalence of $123(100 \%)$ of the sampled population, whereas in horses, 114 (92.68\%) positivity was obtained.

Conclusion: The results unveil the prevalence of influenza A virus in the population of horses and dogs in the state of Nuevo Leon, which could indicate a possible outbreak of equine and canine influenza in Mexico. We suggest that the prevalence of influenza virus in companion animals be monitored to investigate its epizootic and zoonotic potential, in addition to encouraging the regulation of vaccination in these animal species in order to improve their quality of life.

Key words: Canine Influenza Virus (CIV), Equine Influenza Virus (EIV), Matrix gene (M), seroprevalence.

\section{Introduction}

Influenza is a highly contagious disease caused by influenza virus. In nature, this virus has a wide range of hosts and is responsible for panzootic, epizootics and pandemics around the world, affecting the health of both humans and animals, and inflicting a heavy socioeconomic burden. Usually, most viruses are restricted to their original host, however, there is evidence of the emergence of zoonotic strains that can replicate and spread within and between animal species (Wiwanitkit et al., 2014).

Canine Influenza Virus (CIV) is a zoonotic infection that spread from horses to dogs (Crawford et al., 2005) and birds (Song et al., 2008). The virus has since established within the population of pet and stray dogs, occasionally causing epizootic outbreaks in overcrowded sites such as animal shelters. At present, CIV is currently distributed in at least 30 states of the United States (Voorhees et al., 2017, CDC, 2019). The detection of Equine Influenza Virus (EIV) occurs in sporadic outbreaks around the world, where essentially, the disease is distributed among unvaccinated horses in precarious animal health conditions (Gaiva et al., 2014; Singh et al., 2018; Sack et al., 2019).

Several factors could contribute to the emergence of the Influenza A virus in companion animals such as the absence of vaccination (Gaiva et al., 2014), co-infection with other respiratory agents (Metzger and Sun, 2013) and co-existence with infected animals in poor health conditions (Holt et al., 2010; Hayward et al., 2010). For that reason, monitoring the presence of the influenza virus in these animal populations is necessary to establish preventive measures against this virus. Influenza virus is a member of the Orthomyxoviridae family. This family comprises four species: Influenza $A, B, C$ and $D$ virus, all of them identified through antigenic differences on the nucleoprotein (NP) and matrix protein (M) (Wright et al., 1995). Because of its high conservation within the viral genome (Furuse et al., 2009; Chander et al., 2012), several studies use the matrix gene for the detection of Influenza A virus in diverse animal species (Wallace et al., 1999, Herrmann et al., 2001; Widjaja et al., 2004; Harmon et al., 2010). 
78 In Mexico, the presence of the virus in canine and equine populations has been suspected due to

79 the detection of antibodies in pet dogs (Ramírez et al., 2013) and horses (Blitvich et al., 2010),

80 however, the virus itself has not been detected.

81 Mexico has a population of more than six million horses intended for different activities.

82 Particularly, waste transportation is characterized by poor working conditions and constant

83 contact with other animal species susceptible to Influenza A virus (INEGI, 2014). The stray dog

84 population exceeds 18 million (Cortez et al., 2018), and the probability of Influenza A virus

85 spreading among these animals is high (Gencay et al., 2004; Kasempimolporn et al., 2006; Levy

86 et al., 2008; Beeleer, 2009) because of the absence of a vaccine against CIV in Mexico. The aim

87 of this study was to determine the presence of Influenza A virus in a populations of trash service 88 horses and pet/stray dogs in Nuevo Leon, Mexico through the detection of the matrix gene as 89 well as the prevalence of the virus in this animal population and its need for vaccine protection.

\section{Materials \& Methods}

\section{Ethics statement}

All animal experiments were approved by the Animal Research and Welfare Ethics Committee (CEIBA-2018-024) of the Laboratory of Immunology and Virology of the College of Biological Sciences (FCB), Universidad Autónoma de Nuevo León (UANL) and the sampling was made under the indications of the NOM-062-ZOO-1999. Informed consent was obtained from the owners of the animals for the collection of additional information.

\section{Study area and collection of samples}

101

102

The samples were obtained in the period between March of 2013 to December of 2015 from 9 municipalities (Apodaca, Cadereyta Jimenez, Escobedo, Guadalupe, Juarez, Montemorelos, Monterrey, San Nicolas de los Garza and Zuazua) of Nuevo Leon, Mexico. The College of Veterinary Medicine and Zootechnics (FMVZ), UANL sampled domestic dogs with acute respiratory symptoms. Of this dog population, 58 nasal swabs, 5 lung necropsies and 5 conjunctival swabs were obtained. For the canine serological study, 123 samples were collected from stray dogs in Guadalupe and Juarez, Nuevo León. None of the dogs had a travel history and none had been vaccinated against CIV. Samples (123 sera and 8 nasal swabs) were also collected from trash service horses. Swabs and necropsies were kept in MEM medium additioned with antibiotic-antimycotic Gibco ${ }^{\circledR}$ (Thermo fisher scientific, Massachusetts, USA) $2 \%$ and stored at $-70{ }^{\circ} \mathrm{C}$ until use. Blood samples were obtained from venipuncture and centrifuged at 3,000 rpm to obtain the serum, which was stored at $-20{ }^{\circ} \mathrm{C}$ until use.

\section{Sample collection}

115 Samples of necropsies and nasal and conjunctival swabs were used to obtain viral RNA. The 116 
117 populations analyzed. Analysis of seroprevalence in stray dogs and trash service horses was

118

119

120

121

122

123

124

125

126

127

128

129

130

131

132

133

134

135

136

137

138

139

140

141

142

143

144

145

146

147

148

149

150

151

152

153

154

155

156

performed on randomly selected samples.

RNA isolation and $M$ gene amplification

Viral RNA was purified from lung necropsies, nasal and conjunctival swabs using AxyPrep ${ }^{\mathrm{TM}}$ Body Fluid Viral DNA/RNA Miniprep Kit (AxygenBioscience, Union city, USA) following the manufacturer's protocol. Coding region of 756 bp of M gene was obtained by SuperScript ${ }^{\circledR}$ III One-Step RT-PCR system with Platinum ${ }^{\circledR}$ Taq High Fidelity (Thermo fisher scientific, Massachusetts, USA) using M specific primers (5'CACGGATCCAAGATGAGTCTTCTAACCGAC-3' and 5'CACGTCGACAGGATCACTTGAATCGCTGCA-3'). Subsequently, a second PCR was performed using oligonucleotides recommended by the World Health Organization (WHO) for Influenza A virus detection (5'-ATGAGYCTTYTAACCGAGGTCGAAACG-3' and 5'TGGACAAANCGTCTACGCTGCAG-3') obtaining a 244 bp PCR product. RNA from the vaccines Fluvac Innovator Pfizer Equine Influenza Vaccine (A2/Kentucky/97) and Vanguard Plus 5 L4 Vaccine were used as controls. Amplification product was visualized on a 1.5\% agarose gel and then sequenced to confirm its genetic identity.

\section{Sequence analysis and phylogenetic tree}

Products of the expected size (244 bp), were purified using Wizard ® SV Gel and PCR clean-up system (Promega, Wisconsin, USA) and directly sequenced by an automated system (Perkin Elmer/Applied Biosystem, California, USA) at the Institute of Biotechnology of the Universidad Nacional Autónoma de México (IBT-UNAM). The sequence analysis was done using CLUSTAL W/BioEdit sequence alignment v7.0 (Hall et al., 1999) and MEGAX software (Kumar et al., 2018). The partial sequences of M1 obtained in this study were submitted to the GenBank database under accession numbers MH463596, MH463597, MH463598, MH463599, MH463600, MH463601 and MH463602. The phylogenetic tree contains sequences corresponding to the M1 matrix gene of influenza A virus obtained from the Influenza Virus Resource (NCBI) database. Zoonotic reassortants: MK690088, CY050848, MG254077, MU471689; Contemporary isolates: AY737298, HQ237603, MF173290, MH363692, MK690096 and Ancestral strains of CIV and EIV: CY109269, GU433346, DQ124160, CY067361, DQ222916, CY028837, Outgroup: CY125948 and KR077935. Maximum likelihood Jones-Taylor-Thornton (JTT) model was performed to the construction of the phylogenetic tree.

\section{M1 recombinant matrix protein}

A feces sample of a wild bird positive for Influenza A virus (kindly provided by Dr. Jose Ignacio Gonzalez Rojas of the Laboratory of Ornithology, College of Biological Sciences, UANL) was processed to obtain the coding sequence of the M1 gene. The sequence whose identity coincided $100 \%$ with the matrix gene present in subtype H1N1/2009 was subcloned into the expression vector pET-28a $(+)$ (Promega, Wisconsin, USA). Protein expression was carried out in

Peer] reviewing PDF | (2019:05:37519:2:2:NEW 9 Nov 2019) 
157 competent E.coli BL21 bacteria with pET-28(+) and IPTG expression system. Bacteria with 0.4

158 OD $(600 \mathrm{~nm})$ of biomass without IPTG was taken before induction as negative control.

159 Subsequently, the expression was induced and after 5 hours of incubation the protein was

160 purified with an OD of 1.6. Bacteria lysis was carried out by lysozymes and sonication.

161 Purification by HisTrap ${ }^{\mathrm{TM}}$ HP columns (GE Healthcare, USA) under denaturing conditions with

162 urea (4M) was performed. The quantification of the purified protein fractions was performed by

163 a semi quantitative-qualitative method comparing band intensity in the SDS-Page, using bovine

164 albumin fractions as control. The purified protein was analyzed by Western blot to confirm its

165 identity using a monoclonal antibody against influenza virus M1 protein (Abcam, United

166 Kingdom).

167

168

\section{Polyclonal antibodies}

169

New Zealand White rabbits were immunized subcutaneously with recombinant matrix protein at

170 6 different points. For the primary immunization, $1 \mathrm{mg}$ of matrix protein was administered with Freund's complete adjuvant. For booster immunizations, $0.5 \mathrm{mg}$ of protein was administered with Freund's incomplete adjuvant 15 days after the primary immunization and once more 2 weeks after that (Leenaars and Hendriksen, 2005). Blood was collected 15 days after the final immunization and sera was obtained. The conditions of animal protection were followed by NOM-062-ZOO-1999.

\section{Sandwich ELISA assay}

Microtiter plates were coated with dog/horse antibodies diluted in carbonate-bicarbonate buffer $\mathrm{pH} 9.6$ and incubated overnight at $4{ }^{\circ} \mathrm{C}$. After two washes with PBS, the plates were blocked with $5 \%$ non-fat dry milk in PBS at $37{ }^{\circ} \mathrm{C}$ for $1 \mathrm{~h}$. After two washes, recombinant matrix protein was added at a concentration of $40 \mu \mathrm{g} / \mathrm{mL}$ and incubated at $37^{\circ} \mathrm{C}$ for $1 \mathrm{~h}$. The anti-M1 antibody $(1: 7,000)$ produced in rabbit was added and incubated at $37^{\circ} \mathrm{C}$ for $1 \mathrm{~h}$ after two washes. at $37^{\circ} \mathrm{C}$ for $1 \mathrm{~h}$, after two washes. The plates were then washed two times and the ABTS $(2,2$ 'azino-bis [3-ethylbenzothuazoline-6-sulphonic acid]) peroxidase substrate (KPL, Gaithersburg, MD, USA) was added and incubated at $37^{\circ} \mathrm{C}$ for $30 \mathrm{~min}$. The absorbance at $405 \mathrm{~nm}$ was measured using an automatic microplate reader (Digital and Analog Systems, Roma, Italy). Human serum positive for Influenza H1N1/2009 and fetal bovine serum were used as a positive and negative control, respectively. The cut-off value was defined as the mean of the negative control OD $405 \mathrm{~nm}$ values plus three standard deviations.

\section{Results}

Canines and equines with acute respiratory disease were analyzed for the detection of CIV and EIV through the amplification of the matrix gene of the Influenza A virus. The 2015 in 9 municipalities of Nuevo León State, Mexico (Table 1). 
197

198

199

200

201

202

203

204

205

206

207

208

209

210

211

212

213

214

215

216

217

218

219

220

221

222

223

224

225

226

227

228

229

230

231

232

233

234

235

236

Matrix gene amplification of Influenza A virus

Of the total samples, the matrix gene was amplified in $13(19.11 \%)$ nasal swabs, $2(2.94 \%)$ conjunctival swabs and $5(7.35 \%)$ lung necropsies, giving a total of $20(29.41 \%)$ positive samples in dog population. Meanwhile, $6(75 \%)$ positive samples of equine nasal swab were amplified. All viruses detected were isolated from unvaccinated animals (Table 1).

\section{Sequence analysis of matrix gene}

Amplicons of $244 \mathrm{bp}$ corresponding to the partial sequence of the matrix gene (M) from canines and equine samples were sequenced. Nucleotide alignments of the analyzed sequences showed a 96-99\% identity with sequences of M1 gene of Influenza A virus. These isolates were compared with matrix sequences of representative strains of clade 1 from American lineage (Florida): $\mathrm{A} / \mathrm{eq} / \mathrm{Miami} / 63, \mathrm{~A} / \mathrm{eq} / \mathrm{Wisconsin} / 03$ and A/canine/Colorado/06, presents 2-6 amino acid substitutions ( $97.18-99.15 \%$ identity). This comparison showed genetic variability in the coding region between amino acids 10 to 80 of $\mathrm{M} 1$, observing greater genetic variability in the canine sequences than in the equine sequences (Figure 1).

The phylogenetic analysis of the sequences shows proximity with zoonotic and potentially pandemic strains such as the H3N2, H1N2 and H1N1/2009. Sequences of equine, canine and avian origin were included to determine the genetic divergence in the partial sequence of the $M$ gene. In this analysis, it is evidenced how the sequences obtained in this study (Mexican isolates) possess a genetic identity of $95.78-97 \%$ with matrix sequences of H3N2 and H1N1 isolates obtained from domestic cats, as well as matrix sequences from isolates of the pandemic strain H1N1/2009 from swine and humans (Zoonotic reassortants). Mexican isolates also have an identity of $92.96-98.6 \%$ with avian, equine and canine contemporary strains. Partial sequences of the $\mathrm{M}$ gene from the ancestral strain of H3N2 and H3N8 of CIV and EIV were included from Genbank, obtaining an identity of 91.55-97.19\% (Figure 2).

\section{Seroprevalence and symptomatology}

A total of 123 sera from canines and 123 sera from equines obtained from 9 municipalities were tested by Sandwich ELISA system. Polyclonal antibodies against recombinant Influenza A matrix protein were founded in the $123(100 \%)$ sera in canines. At least $21.46 \%$ of canine population had been vaccinated against other respiratory viral agents. Meanwhile, 114 (92.68\%) of equines presented polyclonal antibodies against Influenza virus. Vaccine information in equines was only reported against tetanus toxoid.

The population of canines resulting positive for CIV had at least three predominant symptoms: conjunctivitis, runny nose and sneezing. Conjunctivitis and runny nose were presented in $27.94 \%$ of the sampled population, whereas sneezing was observed in at least 10 dogs positive for CIV. The equines reported fewer symptoms, predominantly runny nose and sneezing, both in the sampled population and in the positive samples for EIV (Table 2).

Peer] reviewing PDF | (2019:05:37519:2:2:NEW 9 Nov 2019) 


\section{Discussion}

238

239

240

241

242

243

244

245

246

247

248

249

250

251

252

253

254

255

256

257

258

259

260

261

262

263

264

265

266

267

268

269

270

271

272

273

274

275

276

Although outbreaks of Influenza A virus in dogs and horse populations worldwide have been reported, canine (CIV) and equine influenza virus (EIV) had not been detected in Mexico until now. However, the presence of the virus in pets had already been reported in other parts of the world increasing its incidence in domestic animals (Payungporn et al., 2008; Song et al., 2008; Lee et al., 2010; Lin et al., 2015). In this study, 58 nasal fluid, 5 lung necropsies and 5 conjunctival swabs samples from pet dogs with acute respiratory symptoms were used to detect Influenza A virus through matrix gene amplification with the WHO recommended primers. Of them $13(19.11 \%)$ nasal fluids, 5 (7.35\%) lung necropsies and $2(2.94 \%)$ conjunctival swabs from pet dogs with were positive. Although this value is higher than reported in other studies, this could be explained because all of the sampled animals presented classic symptoms of influenza.

All lung necropsies presented co-infection of Influenza A and other respiratory agents such as Canine Adenovirus type 2, Canine Distemper Virus and Canine Parainfluenza. These coinfections could be an important factor in the severe respiratory diseases suffered by the pet dogs (Unpublished). Co-infection could aggravate the disease and induce the early death of animals (Löhr et al., 2010; Kash et al., 2011; Metzger and Sun, 2013). The detection of viral matrix gene from conjunctival swab samples could reinforce that influenza A virus using the eye as a portal of entry as well as a primary site of virus replication (Belser et al., 2018). Six (75\%) nasal fluid samples from trash service horses that presented characteristic symptoms of Influenza A virus were positive to matrix gene amplification. Although this percentage could be considered high, a recent study showed $96 \%$ of EIV detection in nasopharyngeal swabs from equines in Malaysia during an outbreak in 2015 (Toh et al., 2019).

Although there are many viruses that infect the respiratory tract and they could induce similar symptoms, at present, symptoms such as conjunctivitis, runny nose and sneezing has been observed as the main symptoms related to the detection of CIV and EIV (Spickler, 2016; Sigh et al., 2018). These symptoms that were present in the population of canine and equine analyzed.

In Mexico, there is no CIV vaccination available as a preventive measure against the disease. The vaccination against EIV is not mandatory, thus, the immune status against equine influenza virus is unknow. However, the incidence of EIV in 23 states of United States during 2015 supports the possibility of an outbreak within the equine population (Sack et al., 2019). This population of animals are exposed to multiple risk factors such as work injuries, the contact with waste, and interaction with different animal species (Rimbaud et al., 2006).

The partial nucleotide sequences of the matrix gene showed $96.24-100 \%$ of homology with matrix gene sequences of H1N1, H1N2 and H3N2 subtypes from swine in North America obtained from Genbank. Several studies have shown an incidence of H1N1/2009 subtype in dogs (Dundon et al., 2010; Ozawa et al., 2013; Su et al., 2014; Moon et al., 2015), as well as possible reassortments between H1N1 with H3N2 (Song et al., 2012; Na et al., 2015; Wang et al., 2017). 
277 The comparison of amino acid deduced sequences from equine and canine matrix gene

278 sequences from ancestral strains A/Equine/1963 (H3N8), A/Equine/2003 (H3N8) and

279 A/Canine/2006 (H3N8) indicates that most the residues are highly conserved, obtaining 92.96 -

$28097.19 \%$ of consensus sequences. Divergences at positions V15I, L20P, D30G, N36H, T37K do

281 not represent a significant change in the protein because they are synonymous amino acids to

282 those present in the ancestral strains. Besides, the mutations at positions S17P, Q26E, K35M,

283 S70G, E71G and L74R are present in the C-terminal domain which is characterized as high

284 tolerant to mutations that do not compromise the functionality of the viral protein (Hom et al.,

285 2019).

286 Interestingly, the phylogenetic analysis of the sequences reveals the phylogenetic closeness with

$287 \mathrm{M}$ gene sequences present in strains of zoonotic outbreaks in cats, dogs, swine and humans:

288 (A/Cat/USA/047732/18, A/cat/OR/29573/2009, A/Canine/Ggx/WZ1/2013,

$289 \mathrm{~A} / \mathrm{Sw} / 4 / \mathrm{Mexico} / 2009, \mathrm{~A} / \mathrm{Hu} / \mathrm{Mx} / 007 / 2009)$ with $\mathrm{H} 1 \mathrm{~N} 1$ and H3N2 subtype.

290

291

292

The study of influenza A virus in dogs and horses in Mexico has been limited to the detection of

293 antibodies against the virus. The high seroprevalence obtained in the analysis of antibodies from

294

295 stray dogs and equines evidences the susceptibility to the influenza A virus among animals in precarious conditions of care. It would be interesting to know whether these antibodies are

296 present in protective levels.

297 Pet dogs' studies in Mexico of have shown a low seropositivity against H1N1/2009, H3N2

298

299 $(0.9 \%)$ and H3N8 subtype (4\%) (Ramirez et al., 2013). On the other hand, studies of canines from animal shelters suggest that prolonged exposure to the virus from other infected dogs

300 considerably increases the seropositivity of the animals analyzed from $15 \%$ to $71 \%$ after 8 days 301 the permanence of stray dogs in animal shelters. of confinement (Holt et al., 2010). A limiting factor in this study is the lack of information about

302 The seropositivity of horses analyzed in this study (92.68\%) was greater than $57.89 \%$ reported in Nuevo León in 2010 (Blitvich et al., 2010). However, this percentage is similar to that reported by Gaíva e Silva et al., in unvaccinated horses from Brazil during an outbreak in 2014, where they found a seroprevalence of $92 \%$.

307 Interspecies transmission of Influenza A virus is still unclear. Nevertheless, some animal species could have a role as a mixing vessel of segments that would give rise to potentially zoonotic subtypes. Among these species, domestic animals such as pet dogs and horses stand out (Parrish et al., 2015; Chen et al., 2018). Because these species are companion animals for humans, the presence of Influenza virus in these species could represent a public health risk for both human and animal populations.

313

314

\section{Conclusions}


Our results unveil the prevalence of Influenza A virus in the population of horses and dogs in the state of Nuevo León, Mexico. Because CIV and EIV have spread horizontally among the population of dogs and horses across the United States, the detection of the Influenza A virus in canines and horses in the state of Nuevo Leon, Mexico is not surprising.

The detection of the $\mathrm{M}$ gene and antibodies against the matrix protein provide an effective identification of the Influenza A virus in dogs and horses because of the genetic and antigenic stability of the $\mathrm{M}$ gene. This becomes important due to the constant variability of the virus and its need for constant epidemiological surveillance. Vaccination plays an essential role in stopping the spread of the virus, so we suggest that vaccination systems should be updated and regulated to improve the health conditions of species susceptible to the virus.

\section{Acknowledgements}

This work was supported by grant No. 557222 from the National Council for Science and Technology, Mexico (CONACYT) and grant CN391-15-PAICYT from the Universidad Autónoma de Nuevo León, México. Claudia Bernardette Plata Hipólito was recipient of a fellowship from CONACYT, México. English Language editing support by M.Sc. Alejandra E. Arreola-Triana from Universidad Autónoma de Nuevo León.

\section{References}

1. Beeleer E. 2009. Influenza in dogs and cats. Veterinary Clinics of North America: Small Animal Practice. 39:251-264. DOI 10.1016/j.cvsm.2008.10.011.

2. Belser JA, Lash RR, Garg S, Tumpey TM, Maines TR. 2018. The eyes have it: influenza virus infection beyond the respiratory tract. Lancet Infectology Disease. 18:220-227. DOI: 10.1016/S1473-3099(18)30102-6.

3. Blitvich BJ, Ibarra LA, Cortes AJ, Root JJ, Franklin AB, Sullivan HJ, Fernandez I. 2010. Seroprevalence of equine influenza virus in northeast and southern Mexico. Veterinary Record. 166:565-567. DOI: 10.1136/vr.b4845.

4. Centers for Disease Control and Prevention (CDC): Key Facts about Canine Influenza (Dog Flu). Available at: https://www.cdc.gov/flu/other/canine-flu/keyfacts.html.

5. Chander Y, Jindal N, Sreevatsan S, Stallknecht DE, Goyal SM. 2012. Molecular and phylogenetic analysis of matrix gene of avian influenza viruses isolated from birds and live bird markets in the USA. Influenza and Other Respiratory Viruses. 7:513-520. DOI: 10.1111/irv.12003.

6. Chen Y, Trovao NS, Wang G, Zhao W, He P, Zhou H, Mo Y, Wei Z, Ouyang K, Huang W, Garcia A, Nelson MI. 2018. Emergence and evolution of novel reassortant Influenza A viruses in canines in Southern China. mBio. 9:e00909-18. DOI: 10.1128/mBio.00909-18.

7. Cortez GR, Jimenez M, Gutierrez E, Ortega A. 2018. Stray dog population in a city of southern Mexico and its impact on the contamination of public areas. Veterinary Medicine International. 2381583:6. DOI: 10.1155/2018/2381583. 
356

357

358

359

360

361

362

363

364

365

366

367

368

369

370

371

372

373

374

375

376

377

378

379

380

381

382

383

384

385

386

387

388

389

390

391

392

393

394

8. Crawford PC, Dubovi EJ, Castleman WL, Stephenson I, Gibbs EPJ, Chen L, Smith C, Hill RC, Ferro P, Pompey J, Bright RA, Medina MJ, Johnson CM, Olsen CW, Cox NJ, Klimov AI, Katz JM, Donis RO. 2005. Transmission of Equine Influenza virus to Dogs. Science. 310: 482. DOI: 10.1126/science.1117950.

9. Dundon WG, De Benedictis P, Viale E, Capua I. 2010. Serologic Evidence of Pandemic (H1N1) 2009 Infection in Dogs, Italy. Emerging Infectious Diseases. 16:20192021. DOI: $10.3201 /$ eid1612.100514.

10. Furuse Y, Suzuki A, Kamigaki T, Oshitani H. 2009. Evolution of the M gene of the influenza A virus in different host species: large-scale sequence analysis. Virology Journal. 6:67. DOI: 10.1186/1743-422X-6-67.

11. Gaíva L, Costa AM, Cassaro EM, Custodio M, Siquetin EM, Castro A, Assis I, Moura D. 2014. Prevalence of antibodies against Influenza virus in non-vaccinated equines from the brazilian pantanal. Revista Do Instituto De Medicina Tropical De Sao Paulo. 56:487-492. DOI: 10.1590/S0036-46652014000600006.

12. Gencay A, Oncel T, Karaoglu T, Sancak AA, Demir AB, Ozkul A. 2004. Antibody prevalence to Canine Distemper Virus (CDV) in stray dogs in Turkey. Revue de Médecine Vétérinaire. 155:432-343. DOI: 10.21276/sjm.2017.2.5.2.

13. Hall TA. 1999. BioEdit: a user-friendly biological sequence alignment editor and analysis program for Windows 95/98/ NT. Nucleic Acids Symposium. 41:95-98.

14. Harmon K, Bower L, Kim W, Pentella M, Yoon K. 2010. A matrix gene-based multiplex real-time RT-PCR for detection and differentiation of 2009 pandemic H1N1 and other influenza A viruses in North America. Influenza and Other Respiratory Viruses. 4:405-410. DOI: 10.1111/j.1750-2659.2010.00153.x.

15. Hayward JJ, Dubovi EJ, Scarlett JM, Janeczko S, Holmes EC, Parrish CR. 2010. Microevolution of Canine Influenza Virus in Shelters and Its Molecular Epidemiology in the United States. Journal of Virology. 84:12636-12645. DOI: 10.1128/JVI.01350-10.

16. Herrmann B, Larsson C, Wirgart B. 2001. Simultaneous detection and typing of Influenza Viruses A and B by a Nested Reverse Transcription-PCR: Comparison to Virus Isolation and Antigen Detection by Immunofluorescence and Optical Immunoassay (FLU OIA). Journal of Clinical Microbiology. 39:134-138. DOI: 10.1128/JCM.39.1.134138.2001.

17. Holt DE, Moyer MR, Brown DC. 2010. Serologic prevalence of antibodies against canine influenza virus (H3N8) in dogs in a metropolitan animal shelter. American Veterinary Medical Association. 237: 71-73. DOI: 10.2460/javma.237.1.71.

18. Hom N, Gentles L, Bloom JD, Lee KK. 2019. Deep mutational scan of the highly conserved Influenza A Virus M1 matrix protein reveals substantial intrinsic mutational tolerance. Journal of Virology. 93:1-16. DOI: e00161-19.

19. Instituto Nacional de Estadística y Geografía (INEGI). 2014. Agricultura, ganadería y pesca. Available at: https://www.inegi.org.mx/ 
395

396

397

398

399

400

401

402

403

404

405

406

407

408

409

410

411

412

413

414

415

416

417

418

419

420

421

422

423

424

425

426

427

428

429

430

431

432

433

434

20. Kasempimolporn S, Sichanasai B, Saengseesom W, Puempumpanich S, Chatraporn S, Sitprija V. 2006. Prevalence of rabies virus infection and rabies antibody in stray dogs: A survey in Bangkok, Thailand. Preventive Veterinary Medicine. 78:325-332. DOI: 10.1016/j.prevetmed.2006.11.003.

21. Kash J, Walters K, David AS, Sandouk A, Schwartzman LM, Jagger BW, Chertow DS, Qi L, Kuestner RE, Ozinsky A, Taubenberger JK. 2011. Lethal synergism of 2009 Pandemic H1N1 Influenza Virus and Streptococcus pneumoniae coinfection is associated with loss of murine lung repair responses. mBio. 2:e00172-11. DOI: 10.1128/mBio.00172-11.

22. Kumar S, Stecher G, Li M, Knyaz C, Tamura K. 2018. MEGA X: Molecular Evolutionary Genetics Analysis across Computing Platforms. Molecular Biology and Evolution. 35:1547-1549. DOI: 10.1093/molbev/msy096.

23. Lee C, Jung K, Oh J, Oh T, Han Sm Hwang J, Yeom M, Son D, Kim J, Park B, Moon H, Song D, Kang B. 2010. Protective efficacy and immunogenicity of an inactivated avin-origin H3N2 canine influenza vaccine in dogs challenged with the virulent virus. Veterinary Microbiology. 143:184-188. DOI: 10.1016/j.vetmic.2009.11.037.

24. Leenaars M, Hendriksen CFM. 2005. Critical steps in the production of polyclonal and monoclonal antibodies: Evaluation and recommendations. Institute for Laboratory Animal Research Journal. 46:269-279. DOI: 10.1093/ilar.46.3.269.

25. Levy JK, Crawford PC, Lappin MR, Dubovi EJ, Levy MG, Alleman R, Tucker SJ, Clifford EL. 2008. Infectious diseases of dogs and cats on Isabela Island, Galapagos. Journal of Veterinary Internal Medicine. 22:60-65. DOI: 10.1111/j.19391676.2007.0034.x.

26. Lin HT, Wang CH, Chueh LL, Su BL, Wang LC. 2015. Influenza A(H6N1) Virus in dogs, Taiwan. Emerging Infectious Diseases. 21:2154-2157. DOI: 10.3201/eid2112.141229.

27. Löhr CV, DeBess EE, Baker RJ, Hiett SL, Hoffman KA, Murdoch VJ, Fischer KA, Mulrooney DM, Selman RL, Hammill-Black WM. 2010. Pathology and viral antigen distribution of lethal pneumonia in domestic cats due to pandemic (H1N1) 2009 influenza A virus. Veterinary Pathology. 47:378-386. DOI: 10.1177/0300985810368393.

28. Metzger DW, Sun K. 2013. Immune Dysfunction and bacterial coinfections following influenza. Journal of Immunology. 191:2047-2052. DOI: 10.4049/jimmunol.1301152.

29. Moon H, Hong M, Kim JK, Seon B, Na W, Park SJ, An DJ, Jeoung HY, Kim DJ, Kim JM, Kim SH, Wenny RJ, Webster RG, Kang BK, Song D. 2015. H3N2 canine influenza virus with the matrix gene from the pandemic A/H1N1 virus: infection dynamics in dog and ferrets. Epidemiology and Infection. 14:772-780. DOI: $10.1017 / \mathrm{S} 0950268814001617$.

30. Na W, Lyoo KS, Song E, Hong M, Yeom M, Moon H, Kang B, Kim J, Song D. 2015. Viral dominance of reassortants between canine influenza H3N2 and pandemic (2009) 
435

436

437

438

439

440

441

442

443

444

445

446

447

448

449

450

451

452

453

454

455

456

457

458

459

460

461

462

463

464

465

466

467

468

469

470

471

472

473

474

H1N1 viruses from a naturally co-infected dog. Virology Journal. 12:134. DOI: 10.1186/s12985-015-0343-z.

31. Ozawa M, Kawaoka Y. 2013. Crosstalk between animal and human influenza viruses. Annual Review of Animal Biosciences. 1:21-42. DOI: 10.1146/annurev-animal-031412103733.

32. Parrish CR, Murcia PR, Holmes EC. 2015. Influenza virus reservoirs and intermediate hosts: Dogs, horses, and new possibilities for influenza virus exposures of humans. Journal of Virology. 89:2990-2994. DOI: 10.1128/JVI.03146-14.

33. Payungporn S, Crawford C, Kouo TS, Chen L, Pompey J, Castleman W, Dubovi E, Katz JM, Donis R. 2008. Influenza A virus (H3N8) in Dogs with respiratory disease, Florida. Emerging Infectious Diseases. 14:902-908. DOI: 10.3201/eid1406.071270.

34. Ramírez LA, Contreras M, De la Luz J, Manjarrez M, Rosete DP. Rivera JF, Saavedra M, Ramírez H. 2013. Evidence of transmisión and risk factors for influenza A virus in household dogs and their owners. Influenza and Other Respiratory Viruses. 7:1292-1296. DOI: 10.1111/irv.12162.

35. Rimbaud E, Caballero P, Morales X, Soto JL, Rivera G, Zepeda N, Gutierrez M, Solorzano ME. 2006. Hoof, mouth and skin health situation of working horses from Granada city, Granada, Nicaragua. Revista Electronica Veterinaria. 7:1-12. ISSN 16957504.

36. Sack A, Cullinane A, Daramragchaa, Chuluunbaatar M, Gonchigoo B, Gray GC. 2019. Equine Influenza Virus-A Neglected, Reemergent Disease Threat. Emerging Infectious Diseases. 25:1185-1192. DOI: 10.3201/eid2506.161846.

37. Singh RK, Dhama K, Karthik K, Khandia R, Munjal A, Khurana SK, Chakraborty S, Malik YS, Virmani N, Singh R, Tripathi BN, Munir M, Kolk JV. 2018. A Comprehensive Review on Equine Influenza Virus: Etiology, Epidemiology, Pathobiology, Advances in Developing Diagnostics, Vaccines, and Control Strategies. Frontiers in Microbiology. 9:1941. DOI: 10.3389/fmicb.2018.01941.

38. Song D, Kang B, Lee C, Jung K, Ha G, Kang D, Park S, Park B, Oh J. 2008. Transmission of avian influenza virus (H3N2) to Dogs. Emerging Infectious Diseases. 14:741-746. DOI: 10.3201/eid1405.071471.

39. Song D, Moon HJ, An DJ, Jeoung HY, Kim H, Yeom MJ, Hong M, Nam J, Park S, Park B, Oh J, Song M, Webster RG, Kim J, Kang B. 2012. A novel reassortant canine $\mathrm{H} 3 \mathrm{~N} 1$ influenza virus between pandemic H1N1 and canine H3N2 influenza viruses in Korea. Journal of General Virology. 93:551-4. DOI: 10.1099/vir.0.037739-0.

40. Spickler, Anna Rovid. 2016. Canine Influenza. Retrieved from: http://www.cfsph.iastate.edu/DiseaseInfo/factsheets.php

41. Su S, Chen J, Jia K, Khan S, He S, Fu X, Hong M, Sun L, Qi W, Gray G, Li S. 2014. Evidence for subclinical influenza $\mathrm{A}(\mathrm{H} 1 \mathrm{~N} 1)$ pdm09 virus infection among Dogs in Guandong Providence, China. Journal of Clinical Microbiology. 52:1762-1765. DOI: 10.1128/JCM.03522-13. 
475

476

477

478

479

480

481

482

483

484

485

486

487

488

489

490

491

492

493

494

495

496

497

498

499

500

501

502
42. Toh X, Soh ML, Nq MK, Yap SC, Harith N, Fernandez CJ, Huangfu T. 2019. Isolation and characterization of equine influenza virus (H3N8) from an equine influenza outbreak in Malaysia in 2015. Transbound Emerging Disease. 66:1884-1889. DOI: 10.1111/tbed.13218.

43. Voorhees IEH, Glaser AL, Toohey-Kurth K, Newbury S, Dalziel BD, Dubovi EJ, Poulsen K, Leutenegger C, Willgert K, Brisbane L, Richardson J, Holmes EC, Parrish CR. 2017. Spread of Canine Influenza A (H3N2) Virus, United States. Emerging Infectious Diseases. 23: 1950-1957. DOI: 10.3201/eid2312.170246.

44. Wallace LA, McAulay KA, Douglas JD, Elder AG, Stott DJ, Carman WF. 1999. Influenza Diagnosis: From Dark Isolation into the Molecular Light. Journal of Infection. 39:221-226. DOI: 10.1016/S0163-4453(99)90053-1.

45. Wang C, Wang Q, Hu J, Sun H, Pu J, Liu J, Sun Y. 2017. A multiplex RT-PCR assay for detection and differentiation of avian-origin canine $\mathrm{H} 3 \mathrm{~N} 2$, equine-origin $\mathrm{H} 3 \mathrm{~N} 8$, human-origin H3N2, and H1N1/2009 canine influenza viruses. PLoS ONE. 12:e170374. DOI: 10.1371/journal.pone.0170374.

46. Widjaja L, Krauss SL, Webby RJ, Xie T, Webster RG. 2004. Matrix gene of Influenza A viruses isolated from Wild Aquatic Birds: Ecology and Emergence of Influenza A Viruses. Journal of Virology. 78:8771-8779. DOI: 10.1128/JVI.78.16.87718779.2004.

47. Wiwanitkit V. 2014. Cross species influenza: emerging zoonosis. Asian Pacific Journal of Tropical Disease. 4:S642-S643. DOI: 10.1016/S2222-1808(14)60696-4.

48. World Health Organization (WHO). 2009. WHO information for laboratory diagnosis of pandemic (H1N1) 2009 virus in humans. Available at: https: https://www.who.int/csr/resources/publications/swineflu/WHO_Diagnostic_Recommend ationsH1N1_20090521.pdf.

49. Wright KE, Wilson GAR, Novosad D, Dimock C, Tan D, Weber JM. 1995. Typing and subtyping of Influenza Viruses in Clinical Samples by PCR. Journal of Clinical Microbiology. 33:1180-1184. 


\section{Table 1 (on next page)}

Positive samples to Influenza A virus by matrix gene detection in canines and equines from Nuevo Leon State, Mexico. 
1

2

\begin{tabular}{|c|c|c|c|c|}
\hline Host & Type of sample & Municipalities & $\begin{array}{c}\text { Number of } \\
\text { samples }\end{array}$ & $\begin{array}{c}\text { Number of } \\
\text { positives }(\%)\end{array}$ \\
\hline \multirow{8}{*}{ Canines } & \multirow{5}{*}{ Nasal swab } & Monterrey & 4 & $2(15.38)$ \\
\hline & & Escobedo & 13 & $6(46.1)$ \\
\hline & & San Nicolas de los Garza & 32 & $3(23)$ \\
\hline & & Apodaca & 6 & $1(7.6)$ \\
\hline & & Guadalupe & 3 & $1(7.6)$ \\
\hline & \multirow{2}{*}{ Conjunctival swab } & San Nicolas de los Garza & 3 & $1(20)$ \\
\hline & & Apodaca & 2 & $1(20)$ \\
\hline & Lung biopsy & ND & 5 & $5(100)$ \\
\hline \multirow{5}{*}{ Equines } & \multirow{5}{*}{ Nasal swab } & Montemorelos & 1 & $1(16)$ \\
\hline & & Cadereyta & 5 & $4(50)$ \\
\hline & & Monterrey & 1 & 0 \\
\hline & & San Nicolas de los Garza & 1 & $1(16)$ \\
\hline & & Total & 76 & $26(34.2)$ \\
\hline
\end{tabular}


Table 2 (on next page)

Predominant symptoms in the population of canines and equines sampled. 


\begin{tabular}{ccccc}
\hline Symptoms & $\begin{array}{c}\text { Number (\%) of canines with } \\
\text { reported symptoms }\end{array}$ & $\begin{array}{c}\text { Number (\%) of equines with } \\
\text { reported symptoms }\end{array}$ & \multicolumn{2}{c}{ Positive samples } \\
\cline { 4 - 5 } & $18(26.47)$ & $2(25)$ & 10 & Canines \\
\hline Anorexy & $28(41.17)$ & $4(50)$ & 11 & 2 \\
Cough & $16(23.52)$ & $4(50)$ & 10 & 7 \\
Respiratory difficulty & $12(17.64)$ & $2(25)$ & 19 & 2 \\
Fever & $39(57.35)$ & Absent & 13 & 6 \\
Conjunctivitis & $34(50)$ & $7(87.5)$ & 11 & 3 \\
Runny nose & $20(29.41)$ & Absent & 1 & Absent \\
Sneezing & $4(5.88)$ & &
\end{tabular}

1 


\section{Figure 1}

Alignment of reference amino acid sequences of American equine and canine lineage and deduced amino acid sequences obtained in this study.

Genbank: A/equine/Miami/1/1963(H3N8) ACCESSION NUMBER: CY028837, A/equine/Wisconsin/1/03(H3N8) ACCESSION NUMBER: DQ222916, A/canine/Colorado/8880/2006(H3N8) ACCESSION NUMBER: CY067361.

A/Equine/1963 (H3N8) CY028837 A/Equine/2003 (H3N8) DQ222916 A/Canine/2006 (H3N8) CY067361 A/Canine/2015 MH433596 A/Equine/2015 MH433597 A/Canine/2015 MH433598 A/Canine/2015 MH433599 A/Canine/2015 MH433600 A/Equine/2015 MH433601 A/Equine/2015 MH433602

A/Equine/1963 (H3N8) CY028837 A/Equine/2003 (H3N8) DQ222916 A/Canine/2006 (H3N8) CY067361 A/Canine/2015 MH433596 A/Equine/2015 MH433597 A/Canine/2015 MH433598 A/Canine/2015 MH433599 A/Canine/2015 MH433600 A/Equine/2015 MH433601 A/Equine/2015 MH433602

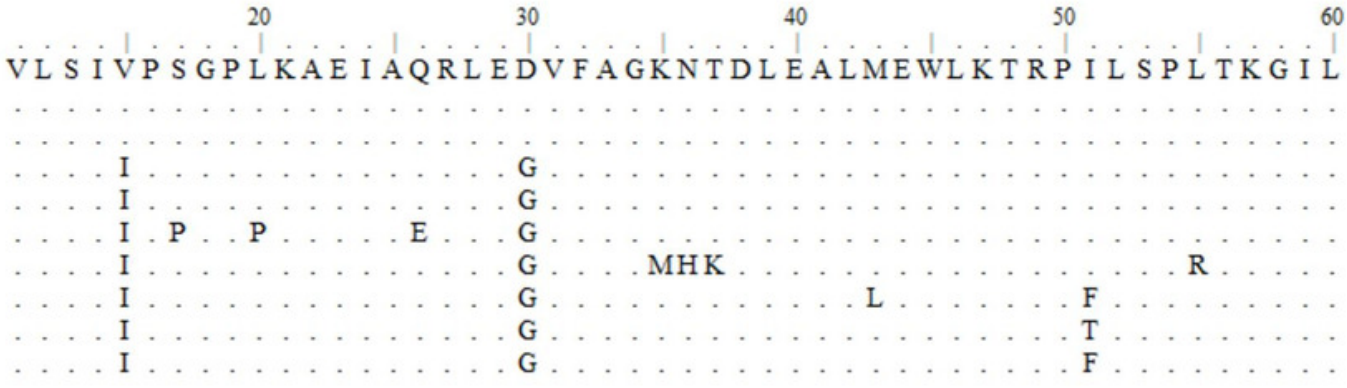

70

80

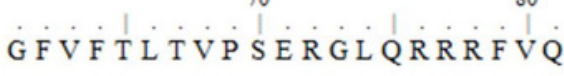

G

G G . R 
Figure 2

Phylogenetic analysis of deduced M1 protein amino acid sequences of canine and equine influenza virus isolations.

The tree was constructed using the neighbor joining method; bootstrap of 1,000 replication (MEGAX).

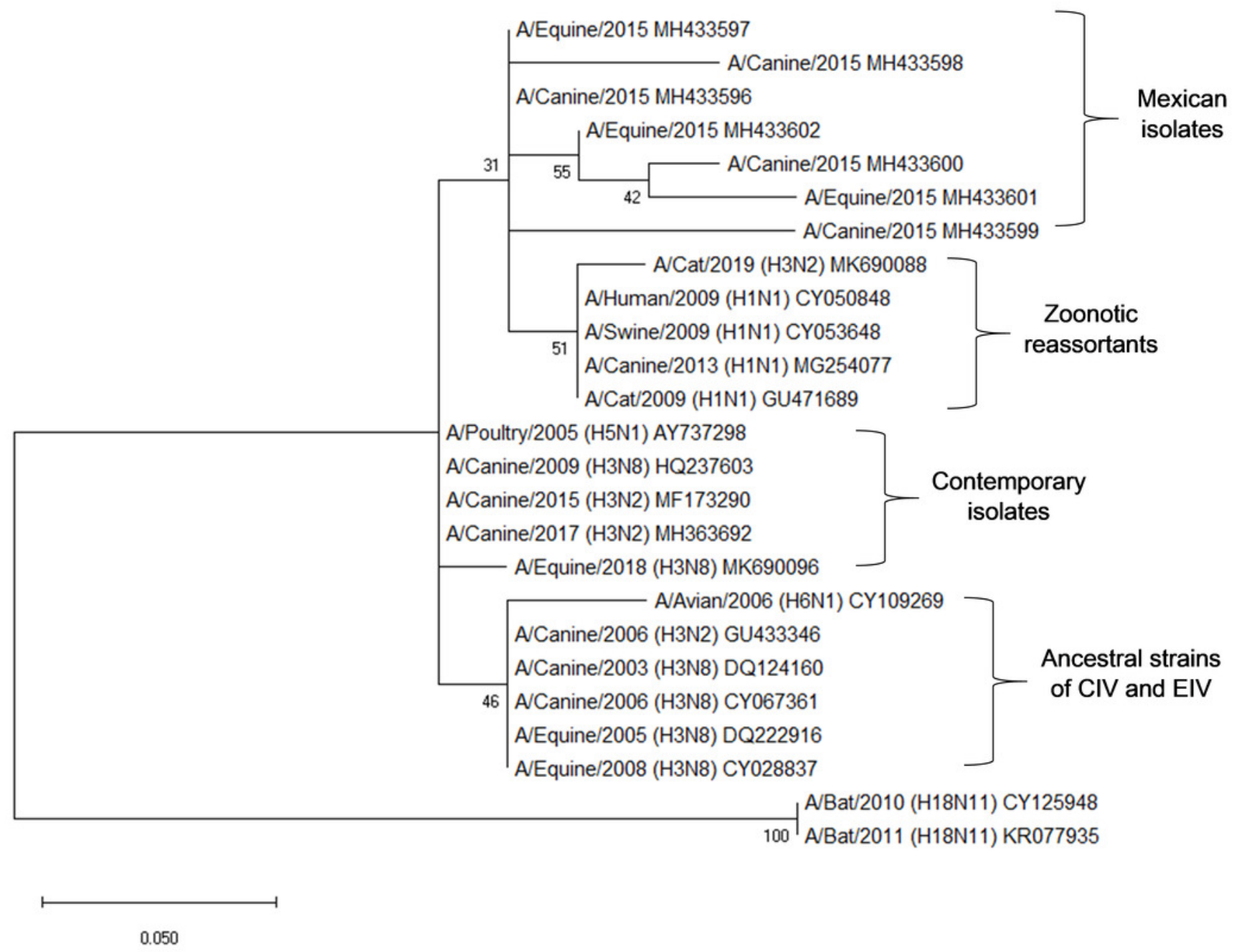

